\section{UMA HISTÓRIA DA INFÂNCIA: DA IDADE MÉDIA À ÉPOCA CONTEMPORÂNEA NO OCIDENTE.}

Colin Heywood

Porto Alegre: Artmed, 2004, 284p.

Passaram-se mais de 25 anos ao longo dos quais a obra de Philippe Ariès, História social da infância e da família, foi traduzida no Brasil e reinou quase solitária como referência para a história da infância ocidental. A publicação do livro de Colin Heywood permite aos leitores brasileiros o acesso a uma competente síntese do avanço dos estudos sobre o tema em alguns países europeus e nos EUA.

Heywood faz um rastreamento de pesquisas produzidas no Reino Unido, na França, nos EUA, bem como na Itália, na Rússia e nos países escandinavos, entre outros. Isso surpreende, pois não é comum encontrarmos obras de autores estrangeiros que reúnam como referências a bibliografia em língua francesa e em língua inglesa. Os estudos sobre a história da infância em nosso país têm se ocupado de algumas dessas pesquisas européias e norte-americanas e das críticas às teses de Ariès, mas as trataram em análises mais pontuais, referidas a um ou outro aspecto do tema.

O livro organiza-se em três partes. A primeira, ocupa-se das mudanças nas concepções de infância a partir da Idade Média. A segunda, trata da relação das crianças com seus pais e com seus pares ao longo das etapas do seu processo de crescimento. A terceira parte dedica-se às crianças no mundo mais amplo, envolvendo o trabalho, a saúde e a educação. Mesmo com a grande abrangência de fontes bibliográficas, a linguagem é acessível a um amplo público leitor.

O livro parte da compreensão de que seria simplista considerar a ausência ou a presença do sentimento da infância em um ou outro período da história. Considera mais fru- tífera a busca de diferentes concepções sobre a infância em diferentes tempos e lugares.

O autor identifica várias "descobertas" da infância: nos séculos VI a VII, nos séculos XII a XIV, nos séculos XVI e XVII, no século $X V I I I$ e início do XIX, e no final do XIX e início do XX. A história da infância move-se por "linhas sinuosas", de modo que a criança pode ter sido considerada impura no início do século XX, como o fora na Alta Idade Média. Se há uma mudança de longo prazo em que a progressiva aceitação da necessidade de uma educação escolar prolonga a infância e a adolescência, se há um interesse crescente e uma imagem cada vez mais positiva da infância, os debates assumem uma forma cíclica e não linear. A ambigüidade, nos diferentes momentos, polariza a criança entre a impureza e a inocência, entre as características inatas e as adquiridas, entre a independência e a dependência, entre meninos e meninas.

As relações das crianças com seus pais e pares é discutida sob vários aspectos: o desejo ou não de se ter filhos, o parto, o batismo, a apresentação das crianças à comunidade e a morte de mães e crianças. Heywood constata que até o impacto da medicina moderna, no final do século XIX, ter filhos era um empreendimento arriscado, mas isso não impedia a expectativa de procriação entre aqueles que se casavam.

A seguir, discute a questão das amasde-leite, a alimentação, o vestuário, a higiene, o infanticídio, o abandono. Considera que a natureza dramática de algumas dessas questões, assim como a ampla documentação oriunda de instituições de atendimento e do judiciário, entre outras, favorece a ênfase da historiografia nesses aspectos. Entretanto, pondera que a maioria das crianças terá sido poupada desses traumas, vivendo histórias mais banais.

Quanto à segunda fase da infância, do desmame aos sete anos, identifica contrastan- 
tes formas de atitude dos pais: o tipo indiferente; o tipo "invasivo" ou "evangélico", que vê a criança como pecadora inata; o seu oposto, que a toma como naturalmente inocente: e o tipo moderado. $\bigcirc$ autor cita pesquisas que indicam diferentes modos de comportamento materno e paterno, tanto entre personagens da nobreza e da burguesia como entre trabalhadores, camponeses e escravos norte-americanos.

A seguir, trata dos aprendizados e da educação das crianças: o controle dos esfíncteres, o caminhar, a fala, os brinquedos e brincadeiras, os livros infantis. Amedrontar, ironizar, castigar física e moralmente são formas de tratamento que ocorreram em diferentes momentos, embora também se pudesse identificar o combate a essas práticas, como no século XI, quando Santo Anselmo apontava as vantagens da gentileza e dos bons exemplos.

Aos sete anos marcava-se uma transformação na vida das crianças. Mudavam-se os trajes, diferenciavam-se os gêneros, atribuíam-se responsabilidades. Ampliavam-se as relações sociais, seja pela entrada no mundo do trabalho ou do estudo, muitas vezes com a saída de casa, seja pelo maior convívio com os grupos de pares, que irão rivalizar com a família nas influências sobre a socialização das crianças.

A última parte do livro trata da presença das crianças no mundo do trabalho e da sua saúde e educação. $\bigcirc$ autor considera que, apesar dos exemplos cruéis de exploração do trabalho infantil, grande parte do trabalho feito pelas crianças no passado seria casual e de pouco esforço, relacionado a tarefas de ajudar os adultos nos seus afazeres. Há exemplos de ambas as formas de tratamento, das suaves às extenuantes, no campo e na cidade, antes e após a industrialização. As fábricas intensificaram os abusos sobre as crianças e se isso levou à discussão e formulação de leis, a legislação não chegou a proibir, mas a regulamentar o trabalho infantil e seus efeitos são passíveis de discussão. A condenação e eliminação de boa parte do trabalho infantil, a construção de uma concepção moderna da infância, que destaca a sua vulnerabilidade e que põe a escola como local privilegiado para a infância, foi fruto de um longo processo.

Quanto à saúde, antes da medicina moderna, as crianças eram muito mais vulneráveis a inúmeros problemas, embora as evidências sobre as dificuldades por que passaram não sejam muitas. A melhoria dessa condição, com o passar do tempo, pode ser observada, por exemplo, pelos dados dos registros militares, relacionados à altura dos jovens: adolescentes da classe trabalhadora, nascidos no final da década de 1950, tinham 30 centímetros acima dos nascidos em meados do século XVIII, na Inglaterra. Mas há também estudos que mostram um declínio da estatura, em certos períodos, como entre 1760 e 1800, em Viena, provavelmente relacionado à deterioração dos padrões de vida e suas conseqüências para a nutrição. Outro indicador importante refere-se à mortalidade, que começa a diminuir, aos poucos, a partir do final do século XVIII, e mais efetivamente a partir do final do século XIX. Entretanto, $\mathrm{o}$ autor afirma que a melhoria nos dados estatísticos pode encobrir a persistência das desigualdades sociais: no século XIX, as crianças pobres e trabalhadoras eram mais baixas e morriam em maior número do que as de classe alta.

A substituição do trabalho pela escola, como principal ocupação da criança, fica mais caracterizada no final do século XIX e início do século XX. É uma longa história, que se inicia nos países protestantes do norte europeu, no século XVII. No século XVIII, refor- 
madores começam a pensar em termos de um sistema nacional de educação. Heywood chama a atenção para as pesquisas que se ocupam das experiências educacionais anteriores, no âmbito do aprendizado dos ofícios, no período medieval. Considera ainda, que o acesso à educação também se fez marcar pelas desigualdades econômicas e de gênero e raça.

Nas conclusões, o autor reafirma a recorrência de vários temas nessa longa trajetória, da Alta Idade Média ao século XX. Indica melhorias significativas para sua saúde, educação e bem-estar, assim como o final da crença na impureza da infância. Considera, por fim, que as crianças não teriam sido vítimas passivas, possuindo alguma capacidade de resistência e de escolha.

Algumas críticas e considerações podem ser apresentadas à obra. Inicialmente, à edição brasileira. $\bigcirc$ cuidado com a revisão poderia ter evitado as várias falhas de digitação. $\bigcirc$ mesmo quanto à tradução, que incorre em alguns problemas. No subtítulo da obra, entende-se "tempos modernos" (modern times, no original) como "época contemporânea". Embora o autor, no último capítulo e em alguns poucos momentos do livro, refira-se aos tempos atuais, o seu estudo estende-se de fato ao início do século $X X$, sem ocupar-se das questões ocorridas ao longo do século passado. Em outro momento, para se referir ao controle dos esfíncteres, afirma-se que uma das primeiras tarefas propostas por pais e amas "era o ensinamento de como utilizar o banheiro". Parece haver um receio no uso de expressões como defecar e urinar e aí não se pode dizer se o problema é da tradução ou do texto original. Uma das falhas mais gritantes ocorre na página 178, quando ear deveria ser traduzido por "orelha" e não "ouvido", pois não é factível que, na situação descrita, para castigar uma criança em uma oficina, alguém tenha "martelado um prego em seu ouvido".

Quanto ao texto e à amplitude do período estudado, em alguns momentos, parece que se transita com uma certa ligeireza do período medieval aos séculos XVIII e $X I X$, sem considerar as diferentes condições dos diferentes momentos históricos. Apoiado nas pesquisas realizadas em diversos países, o livro pouco pode falar, ainda, da vida das crianças nos ambientes rurais. Entretanto, o esforço "olímpico" de síntese, como considera o autor, torna essas simplificações quase que inevitáveis.

É louvável a preocupação que acompanha todo o texto, de evitar uma compreensão da história como seqüência linear e evolutiva, assim como, por conseqüência, o entendimento de que, em cada momento haveria uma única infância, o que representa um grande avanço em relação às teses de Ariès. Mas ainda persiste, em vários momentos, uma certa compreensão hierarquizada das formas de sentimento e de relação entre adultos e crianças, como se os sentimentos mais positivos brotassem das classes superiores, irradiando-se para as inferiores.

Em outros momentos, a ponderação das ambigüidades pode levar a uma minimização das situações de exploração infantil, como na página 179, em que o autor afirma que "de forma nenhuma estas eram vítimas passivas da exploração" e que, de algum modo, "as crianças conseguiam transformar o chão de fábrica em um lugar de diversão para si próprias, subvertendo a atenção dos adultos ao seu redor". É necessário, de fato, metodologicamente, evitar as interpretações generalizadas, que acabam por ajuizar que tais ou quais crianças tiveram ou não tiveram infância. Por isso, é importante buscar as evidências de como a condição infantil se ma- 
nifesta, mesmo nas condições mais adversas. Mas também é preciso estar atento para não se cair no pólo oposto e considerar que essas crianças seriam felizes e independentes diante de uma relação de forças tão desigual como as que têm com os adultos.

Finalmente, cabe uma consideração do lado de cá, do hemisfério sul. A história ocidental ainda é contada no livro, como se não existíssemos, como se a colonização, o ouro, a prata, a batata e tantas outras coisas não fizessem parte da história do ocidente. Isso também remete à expressão "ocidental", que retira explicitamente da análise os aspectos das relações com as sociedades e culturas orientais, que têm suas implicações na nossa história da infância. Para ser mais coerente com a preocupação em se considerar as diferentes condições sociais, culturais etc., para uma compreensão mais consistente da História, caberia referir-se à história da humanidade.

É claro que isso parece pedir demais, o que é fácil de se fazer em uma ligeira apreciação. Mas não custa indicar caminhos de reflexão para as nossas análises e pesquisas, sem deixar de considerar a importância do trabalho do autor, que avança muito mais do que outros, que generalizam para todo o mundo a partir de um único país ou região, ou de uma única referência lingüística.

Recomenda-se a leitura do livro a todos os que tenham interesse na temática.

Moysés Kuhmann Jr.

Departamemto de Pesquisas Educacionais da Fundação Carlos Chagas mkj@fcc.org.br 